Chepok O. O.

\title{
ASYMPTOTIC REPRESENTATIONS OF SOLUTIONS WITH SLOWLY VARYING DERIVATIVES OF THE SECOND ORDER DIFFERENTIAL EQUATIONS WITH THE PRODUCT OF DIFFERENT TYPES OF NONLINEARITIES
}

Significantly nonlinear non-autonomous differential equations have begun to appear in practice from the second half of the nineteenth century in the study of real physical processes in atomic and nuclear physics, and also in astrophysics. The differential equation, that contains in its right part the product of regularly and rapidly varying nonlinearities of an unknown function and its first-order derivative is considered in the paper. Partial cases of such equations arise, first of all, in the theory of combustion and in the theory of plasma. The first important results on the asymptotic behavior of solutions of such equations have been obtained for a second-order differential equation, that contains the product of power and exponential nonlinearities in its right part. For, no such equations have been obtained before. According to this, the study of the asymptotic behavior of solutions of nonlinear differential equations of the second order of general case, that contain the product of regularly and rapidly varying nonlinearities as the argument tends either to zero or to infinity, is actual not only from the theoretical but also from the practical point of view. The asymptotic representations, as well as the necessary and sufficient conditions of the existence of $P_{\omega}\left(Y_{0}, Y_{1}, \pm \infty\right)$-solutions of such equations are investigated in the paper. This class of solutions is the one of the most difficult of studying due to the fact that, by the a priori properties of the functions of the class, their second-order derivatives aren't explicitly expressed through the first-order derivative. The results obtained in this article supplement the previously obtained results for $P_{\omega}\left(Y_{0}, Y_{1}, \pm \infty\right)$-solutions of the investigated equation concerning the sufficient conditions of their existence and quantity.

Key words and phrases: second order differential equations with the product of different types of nonlinearities, rapidly varying functions, regularly varying function, $P_{\omega}\left(Y_{0}, Y_{1}, \lambda_{0}\right)$ solutions, asymptotic representations of solutions and their derivatives.

South Ukrainian National Pedagogical University named after K. D. Ushynsky, Odessa, Ukraine (Chepok O.O.)

e-mail: olachepok@ukr.net (Chepok O.O.)

\section{INTRODUCTION}

The following second order differential equation

$$
y^{\prime \prime}=\alpha_{0} p(t) \varphi_{0}(y) \varphi_{1}\left(y^{\prime}\right)
$$

УДК 517.925

2010 Mathematics Subject Classification: 34A34, 34C41, 34E99.

(C) Chepok O. O., 2020 
is considered. In this equation $\alpha_{0} \in\{-1 ; 1\}$, functions $p:[a, \omega[\rightarrow] 0,+\infty[,(-\infty<a<\omega \leq$ $+\infty)$ and $\left.\varphi_{i}: \Delta_{Y_{i}} \rightarrow\right] 0,+\infty\left[(i \in\{0,1\})\right.$ are continuous, $Y_{i} \in\{0, \pm \infty\}, \Delta_{Y_{i}}$ is either the interval $\left[y_{i}^{0}, Y_{i}\right.$ [ or the interval $\left.] Y_{i}, y_{i}^{0}\right]$. If $Y_{i}=+\infty\left(Y_{i}=-\infty\right)$ we put $y_{i}^{0}>0\left(y_{i}^{0}<0\right)$.

We also suppose that function $\varphi_{1}$ is a regularly varying as $y \rightarrow Y_{1}$ function of index $\sigma_{1}$ ([9], p.10-15), function $\varphi_{0}$ is twice continuously differentiable on $\Delta_{Y_{0}}$ and satisfies the next conditions

$$
\varphi_{0}^{\prime}(y) \neq 0 \text { as } y \in \Delta_{Y_{0}}, \quad \lim _{\substack{y \rightarrow Y_{0} \\ y \in \Delta_{Y_{0}}}} \varphi_{0}(y) \in\{0,+\infty\}, \quad \lim _{\substack{y \rightarrow Y_{0} \\ y \in \Delta_{Y_{0}}}} \frac{\varphi_{0}(y) \varphi_{0}^{\prime \prime}(y)}{\left(\varphi_{0}^{\prime}(y)\right)^{2}}=1 .
$$

It follows from the above conditions (2) that the function $\varphi_{0}$ and its derivative of the first order are rapidly varying functions as the argument tends to $Y_{0}$ ([9], p.15). Thus, the investigated differential equation contains regularly and rapidly varying nonlinearities in its right-hand side.

Partial cases of the equation (1), which contains both power-type and exponential-type nonlinearities in the right-hand side, are found in practice, in particular, in the theory of combustion and in the theory of plasma. For example, during investigations of distribution of electrostatic potential in a cylindrical plasma volume of combustion products it have been aroused the nonlinear differential equation that can be reduced to the next one:

$$
y^{\prime \prime}=\alpha_{0} p(t) e^{\sigma y}\left|y^{\prime}\right|^{\lambda} .
$$

The equation (3) is an equation of the type (1), in which $\varphi_{1}(z)=|z|^{\lambda}, \varphi_{0}(z)=e^{\sigma z}$, $\sigma, \lambda \in \mathbf{R}, \sigma \neq 0$, function $p:[a, \omega[\rightarrow] 0,+\infty[(-\infty<a<\omega \leq+\infty)$ is a continuously differentiable function. Under some restrictions on the function $p(t)$ certain results for the asymptotic behavior of all regular solutions of this equation have been obtained in works of Evtukhov V. M. and Dric N. G.(look [5], for example).

Thus, the equation (1) is a natural generalization of equation (3) and plays an important role in the development of a qualitative theory of differential equations.

The main aim of the article is the investigation of conditions of the existence of following class of solutions of the equation (1).

Definition 1. The solution $y$ of the equation (1), that is defined on the interval $\left[t_{0}, \omega[\subset[a, \omega[\right.$, is called $P_{\omega}\left(Y_{0}, Y_{1}, \lambda_{0}\right)$-solution $\left(-\infty \leq \lambda_{0} \leq+\infty\right)$, if the following conditions take place

$$
y^{(i)}:\left[t_{0}, \omega\left[\longrightarrow \Delta_{Y_{i}}, \quad \lim _{t \uparrow \omega} y^{(i)}(t)=Y_{i} \quad(i=0,1), \quad \lim _{t \uparrow \omega} \frac{\left(y^{\prime}(t)\right)^{2}}{y^{\prime \prime}(t) y(t)}=\lambda_{0} .\right.\right.
$$

This class of solutions was defined in the work of V. M. Evtukhov [3] for the $n$-th order differential equations of Emden-Fowler type and was concretized for the second-order equation. Due to the asymptotic properties of functions in the class of $P_{\omega}\left(Y_{0}, Y_{1}, \lambda_{0}\right)$-solutions [6], every such solution belongs to one of four non-intersecting sets according to the value of $\lambda_{0}: \lambda_{0} \in \mathbb{R} \backslash\{0,1\}, \lambda_{0}=0, \lambda_{0}=1, \lambda_{0}= \pm \infty$. In this article we consider the case $\lambda_{0}= \pm \infty$ of such solutions, every $P_{\omega}\left(Y_{0}, Y_{1}, \pm \infty\right)$-solution and its derivative satisfy the following limit relations

$$
\lim _{t \uparrow \omega} \frac{\pi_{\omega}(t) y^{\prime}(t)}{y(t)}=1, \quad \lim _{t \uparrow \omega} \frac{\pi_{\omega}(t) y^{\prime \prime}(t)}{y^{\prime}(t)}=0 .
$$


This class $P_{\omega}\left(Y_{0}, Y_{1}, \pm \infty\right)$-solutions for equations of the form (1) is one of the most difficult to study due to the fact that the second-order derivative is not explicitly expressed through the first-order derivative. From (4) it means that the derivative of the first order of each such solution is a slowly varying function as $t \uparrow \omega$.

From the conditions (2) it also follows that the function $\varphi_{0}$ and its first-order derivative belong to the class $\Gamma_{Y_{0}}\left(Z_{0}\right)$, that was introduced in the works of V. M. Evtukhov and A. G. Chernikova [4] as a generalization of the class $\Gamma$ (L. Khan, see, for example, [1], p. $75)$. The properties of the class $\Gamma_{Y_{0}}\left(Z_{0}\right)$ were used to get our results.

For the equation (1), in previous works [2] the necessary and sufficient conditions for the existence of the investigated class of $P_{\omega}\left(Y_{0}, Y_{1}, \pm \infty\right)$-solutions were established in case of the existence of some infinite limit. In this work we establish the sufficient conditions for the existence of $P_{\omega}\left(Y_{0}, Y_{1}, \pm \infty\right)$-solutions of the equation (1) in case this limit equals nonzero real number. We also have found the asymptotic representations of such solutions and its first order derivatives as $t \uparrow \omega$ and indicated the number of such solutions.

\section{SECTION With RESUlts}

To formulate the main results, we introduce the following definitions

Definition 2. Let $Y \in\{0, \infty\}, \Delta_{Y}$ is some one-sided neighborhood of $Y$. Continuousdifferentiable function $\left.L: \Delta_{Y} \rightarrow\right] 0 ;+\infty[$ is called ( [8], p.2-3) a normalized slowly varying function as $z \rightarrow Y \quad\left(z \in \Delta_{Y}\right)$ if the next statement is valid

$$
\lim _{\substack{y \rightarrow Y \\ y \in \Delta_{Y}}} \frac{y L^{\prime}(y)}{L(y)}=0 .
$$

Definition 3. We say that a slowly varying as $z \rightarrow Y \quad\left(z \in \Delta_{Y}\right)$ function $\left.\theta: \Delta_{Y} \rightarrow\right] 0 ;+\infty[$ satisfies the condition $S$ as $z \rightarrow Y$, if for any continuous differentiable normalized slowly varying as $z \rightarrow Y \quad\left(z \in \Delta_{Y}\right)$ function $\left.L: \Delta_{Y_{i}} \rightarrow\right] 0 ;+\infty[$ the next relation is valid

$$
\theta(z L(z))=\theta(z)(1+o(1)) \quad \text { as } \quad z \rightarrow Y \quad\left(z \in \Delta_{Y}\right) .
$$

Condition $S$ is satisfied, for example, for such functions as $\ln |y|,\left.|\ln | y\right|^{\mu}(\mu \in R), \ln \ln |y|$.

The following theorem is obtained in our previous work [2] and contains a necessary conditions for the existence the $P_{\omega}\left(Y_{0}, Y_{1}, \pm \infty\right)$-solution of the equation (1).

Theorem 1. [2] Let for equation (1) $\sigma_{1} \neq 1$, the function $\varphi_{1}\left(y^{\prime}\right)\left|y^{\prime}\right|^{-\sigma_{1}}$ satisfies the condition $S$ as $y^{\prime} \rightarrow Y_{1} \quad\left(y^{\prime} \in \Delta_{Y_{1}}\right)$ Then, each $P_{\omega}\left(Y_{0}, Y_{1}, \pm \infty\right)$-solution of the differential equation (1) can be represented as

$$
y(t)=\pi_{\omega}(t) L(t),
$$

where $L:\left[t_{0}, \omega\left[\rightarrow R\right.\right.$ is twice continuously differentiable on $\Delta_{Y_{0}}$ and satisfies the next conditions

$$
\begin{gathered}
y_{0}^{0} \pi_{\omega}(t) L(t)>0, \quad L^{\prime}(t) \neq 0 \quad \text { as } \quad t \in\left[t_{1}, \omega\left[\left(t_{0} \leq t_{1}<\omega\right),\right.\right. \\
\lim _{t \uparrow \omega} L(t) \in\{0 ; \pm \infty\}, \quad \lim _{t \uparrow \omega} \pi_{\omega}(t) L(t)=Y_{0}, \quad \lim _{t \uparrow \omega} \frac{\pi_{\omega}(t) L^{\prime}(t)}{L(t)}=0 .
\end{gathered}
$$


Thus, in the case of the existence of a finite or infinite limit

$$
\lim _{t \uparrow \omega} \frac{\pi_{\omega}(t) L^{\prime \prime}(t)}{L^{\prime}(t)}
$$

the following relations take place

$$
\begin{gathered}
\lim _{t \uparrow \omega} \frac{\pi_{\omega}(t) L^{\prime \prime}(t)}{L^{\prime}(t)}=-1, \quad \alpha_{0} L^{\prime}(t)>0 \quad \text { as } \quad t \in\left[t_{1}, \omega\left[\left(t_{0} \leq t_{1}<\omega\right),\right.\right. \\
p(t)=\frac{\alpha_{0} L^{\prime}(t)}{\varphi_{1}(L(t)) \varphi_{0}\left(\pi_{\omega}(t) L(t)\right)}[1+o(1)] \quad \text { as } \quad t \uparrow \omega .
\end{gathered}
$$

Let's introduce the following definition.

Definition 4. We say that the condition $N$ is satisfied for the equation (1) if for some continuously differentiable function $L(t):\left[t_{0}, \omega\left[\longrightarrow R\left(t_{0} \in[a, \omega[)\right.\right.\right.$, which satisfies conditions (6) $-(7)$ and (8), the following representation takes place

$$
p(t)=\frac{\alpha_{0} L^{\prime}(t)}{\varphi_{1}(L(t)) \varphi_{0}\left(\pi_{\omega}(t) L(t)\right)}[1+r(t)]
$$

where $r(t):\left[t_{0}, \omega[\longrightarrow]-1 ;+\infty[\right.$ us a continuous function that tends to zero as $t \uparrow \omega$.

To formulate the sufficient conditions for the existence the $P_{\omega}\left(Y_{0}, Y_{1}, \pm \infty\right)$-solution of the equation (1) let's introduce some notations.

$$
\begin{gathered}
\mu_{0}=\operatorname{sign} \varphi_{0}^{\prime}(y), \quad \theta_{1}\left(y^{\prime}\right)=\varphi_{1}\left(y^{\prime}\right)\left|y^{\prime}\right|^{-\sigma_{1}}, \\
H(t)=\frac{L^{2}(t) \varphi_{0}^{\prime}\left(\pi_{\omega}(t) L(t)\right)}{L^{\prime}(t) \varphi_{0}\left(\pi_{\omega}(t) L(t)\right)}, \quad q_{1}(t)=\left.\frac{\left(\frac{\varphi_{0}^{\prime}(y)}{\varphi_{0}(y)}\right)^{\prime}}{\left(\frac{\varphi_{0}^{\prime}(y)}{\varphi_{0}(y)}\right)^{2}}\right|_{y=\pi_{\omega}(t) L(t)}, \\
e_{1}(t)=1+\frac{\pi_{\omega}(t) L^{\prime}(t)}{L(t)}, \quad e_{2}(t)=2+\frac{\pi_{\omega}(t) L^{\prime \prime}(t)}{L^{\prime}(t)} .
\end{gathered}
$$

For these functions, from (2), (6) and (7) the following statements are fulfilled:

1)

$$
\lim _{t \uparrow \omega} e_{1}(t)=\lim _{t \uparrow \omega} e_{2}(t)=1, \quad \lim _{t \uparrow \omega} H(t)= \pm \infty, \quad \lim _{t \uparrow \omega} q_{1}(t)=0,
$$

2) If the next limit

$$
\lim _{t \uparrow \omega} \frac{L(t)}{L^{\prime}(t)} \cdot \frac{H^{\prime}(t)}{|H(t)|^{\frac{3}{2}}},
$$

exists, then

$$
\lim _{t \uparrow \omega} \frac{L(t)}{L^{\prime}(t)} \cdot \frac{H^{\prime}(t)}{|H(t)|^{\frac{3}{2}}}=0 .
$$

The sufficient conditions for the existence the of $P_{\omega}\left(Y_{0}, Y_{1}, \pm \infty\right)$-solutions of the equation (1) in case 


$$
\lim _{t \uparrow \omega} \frac{\pi_{\omega}(t) L^{\prime}(t)}{L(t)}|H(t)|^{\frac{1}{2}}= \pm \infty
$$

were found in [2].

In this work we suppose that

$$
\lim _{t \uparrow \omega} \frac{\pi_{\omega}(t) L^{\prime}(t)}{L(t)}|H(t)|^{\frac{1}{2}}=\gamma, \quad 0<|\gamma|<+\infty .
$$

The sufficient conditions for this case are formulated in the following theorem

Theorem 2. Let for equation (1) $\sigma_{1} \neq 1$, the function $\varphi_{1}\left(y^{\prime}\right)\left|y^{\prime}\right|^{-\sigma_{1}}$ satisfies the condition $S$ as $y^{\prime} \rightarrow Y_{1} \quad\left(y^{\prime} \in \Delta_{Y_{1}}\right)$, the conditions $N$, (12) and (13) are taken place.

Then in case $\alpha_{0} \mu_{0}>0$, the differential equation (1) has a one-parameter family of $P_{\omega}\left(Y_{0}, Y_{1}, \pm \infty\right)$-solutions,

in case $\alpha_{0} \mu_{0}<0$ and $y_{0}^{0} \alpha_{0} \gamma \pi_{\omega}(t)<0$ the differential equation (1) has a two-parameter family of $P_{\omega}\left(Y_{0}, Y_{1}, \pm \infty\right)$-solutions,

and in case $\alpha_{0} \mu_{0}<0$ and $y_{0}^{0} \alpha_{0} \gamma \pi_{\omega}(t)>0$ the differential equation (1) has at least one of $P_{\omega}\left(Y_{0}, Y_{1}, \pm \infty\right)$-solutions.

For each of such solutions the following asymptotic representations take place as $t \uparrow \omega$.

$$
\begin{gathered}
y(t)=\pi_{\omega}(t) \cdot L(t)+\frac{\varphi_{0}\left(\pi_{\omega}(t) L(t)\right)}{\varphi_{0}^{\prime}\left(\pi_{\omega}(t) L(t)\right)} \cdot o(1), \\
y^{\prime}(t)=\left[L(t)+\pi_{\omega}(t) \cdot L^{\prime}(t)\right] \cdot\left[1+|H(t)|^{-\frac{1}{2}} \cdot o(1)\right] .
\end{gathered}
$$

Proof. We apply to the equation (1) the transformation

$$
\left\{\begin{array}{l}
y(t)=\pi_{\omega}(t) \cdot L(t)+\frac{\varphi_{0}\left(\pi_{\omega}(t) \cdot L(t)\right)}{\varphi_{0}^{\prime}\left(\pi_{\omega}(t) \cdot L(t)\right)} \cdot z_{1}(t), \\
y^{\prime}(t)=\left[L(t)+\pi_{\omega}(t) \cdot L^{\prime}(t)\right] \cdot\left[1+z_{2}(t)\right],
\end{array}\right.
$$

and reduce the system (16) into the following system of differential equations

$$
\left\{\begin{array}{l}
z_{1}^{\prime}=L(t) \cdot e_{1}(t) \cdot \frac{\varphi_{0}^{\prime}\left(\pi_{\omega}(t) L(t)\right)}{\varphi_{0}\left(\pi_{\omega}(t) L(t)\right)} \cdot\left[q_{1}(t) z_{1}+z_{2}\right], \\
z_{2}^{\prime}=\frac{L^{\prime}(t)}{L(t)} \cdot \frac{e_{2}(t)}{e_{1}(t)} \times \\
\times\left[\frac{\alpha_{0} p(t)\left|e_{1}(t) \cdot L(t)\right|^{\sigma_{1}} \theta_{1}(L(t)) \varphi_{0}\left(Y_{1}\left(t, z_{2}\right)\right) \cdot K\left(t, z_{2}\right)}{L^{\prime}(t) \cdot e_{2}(t)} \cdot\left[1+z_{2}\right]^{\sigma_{1}}-\left[1+z_{2}\right]\right],
\end{array}\right.
$$

in which

$$
\begin{gathered}
K\left(t, z_{2}\right)=\frac{\theta_{1}\left(Y_{2}\left(t, z_{2}\right)\right)}{\theta_{1}(L(t))}, \quad Y_{1}\left(t, z_{1}\right)=\pi_{\omega}(t) L(t)+\frac{\varphi_{0}\left(\pi_{\omega}(t) L(t)\right)}{\varphi_{0}^{\prime}\left(\pi_{\omega}(t) L(t)\right)} \cdot z_{1}, \\
Y_{2}\left(t, z_{2}\right)=\left[L(t)+\pi_{\omega}(t) L^{\prime}(t)\right] \cdot\left[1+z_{2}\right] .
\end{gathered}
$$


From the conditions that $\frac{\left[L(t)+\pi_{\omega}(t) L^{\prime}(t)\right]}{L(t)} \cdot\left[1+z_{2}(t)\right]$ is a slowly varying function, the function $\theta_{1}$ satisfies the condition $S$, we have

$$
\lim _{t \uparrow \omega} K\left(t, z_{2}\right)=1 \text { uniformly on } z_{2} \in\left[-\frac{1}{2}, \frac{1}{2}\right] \text {. }
$$

According to the condition $N$ we have

$$
\frac{\alpha_{0} p(t)|L(t)|^{\sigma_{1}} \theta_{1}(L(t)) \varphi_{0}\left(Y_{1}\left(t, z_{1}\right)\right)}{L^{\prime}(t)}=\frac{\varphi_{0}\left(Y_{1}\left(t, z_{1}\right)\right)}{\varphi_{0}\left(\pi_{\omega}(t) L(t)\right)}[1+r(t)]
$$

Decomposing the right-hand side of (19) at a fixed $t \in\left[t_{1} ; \omega[\right.$ by the Maclaurin formula up to the second order in a variable $z_{1}$ with a Lagrange-shaped residue, we have

$$
\frac{\varphi_{0}\left(Y_{1}\left(t, z_{1}\right)\right)}{\varphi_{0}\left(\pi_{\omega}(t) L(t)\right)} \cdot[1+r(t)]=[1+r(t)] \cdot\left(1+z_{1}\right)+R\left(t, z_{1}\right)
$$

in which

$$
\begin{gathered}
R\left(t, z_{1}\right)=[1+r(t)] \cdot \frac{\varphi_{0}^{\prime \prime}\left(\pi_{\omega}(t) L(t)+\frac{\varphi_{0}\left(\pi_{\omega}(t) \cdot L(t)\right)}{\varphi_{0}^{\prime}\left(\pi_{\omega}(t) \cdot L(t)\right)} \cdot \xi\right) \varphi_{0}\left(\pi_{\omega}(t) L(t)\right)}{\varphi_{0}^{\prime}\left(\pi_{\omega}(t) L(t)\right)} \cdot z_{1}^{2}, \\
|\xi|<\left|z_{1}\right| . \\
\left.Y_{1}\left(t, z_{1}\right)=\pi_{\omega}(t) L(t)\right)\left[1+\frac{1}{\frac{\left.\pi_{\omega}(t) L(t)\right) \varphi_{0}^{\prime}\left(\pi_{\omega}(t) L(t)\right)}{\varphi_{0}\left(\pi_{\omega}(t) L(t)\right)} \xi}\right]
\end{gathered}
$$

From the conditions (2) and (16) it follows that

$$
\begin{gathered}
\varphi_{0}^{\prime \prime}\left(\pi_{\omega}(t) L(t)+\frac{\varphi_{0}^{\prime}\left(\pi_{\omega}(t) \cdot L(t)\right)}{\varphi_{0}\left(\pi_{\omega}(t) \cdot L(t)\right)} \cdot \xi\right)=\frac{\varphi_{0}^{\prime 2}\left(\pi_{\omega}(t) L(t)+\frac{\varphi_{0}^{\prime}\left(\pi_{\omega}(t) \cdot L(t)\right)}{\varphi_{0}\left(\pi_{\omega}(t) \cdot L(t)\right)} \cdot \xi\right)}{\varphi_{0}\left(\pi_{\omega}(t) L(t)+\frac{\varphi_{0}^{\prime}\left(\pi_{\omega}(t) \cdot L(t)\right)}{\varphi_{0}\left(\pi_{\omega}(t) \cdot L(t)\right)} \cdot \xi\right)} \times \\
\times\left[1+d_{1}\left(t, z_{1}\right)\right],
\end{gathered}
$$

where

$$
\lim _{t \uparrow \omega} d_{1}\left(t, z_{1}\right)=0 \text { uniformly on } z_{1} \in\left[-\frac{1}{2}, \frac{1}{2}\right] .
$$

It follows from the lemma 1.2. at [4] that if $\varphi_{0}, \varphi_{0}^{\prime} \in \Gamma_{Y_{0}}\left(Z_{0}\right)$ with the additional function $g(y)=\frac{\varphi_{0}(y)}{\varphi_{0}^{\prime}(y)}$, we have

where

$$
\varphi_{0}^{\prime \prime}\left(\pi_{\omega}(t) L(t)+\frac{\varphi_{0}^{\prime}\left(\pi_{\omega}(t) L(t)\right)}{\varphi_{0}\left(\pi_{\omega}(t) L(t)\right)} \cdot \xi\right)=\frac{\varphi_{0}^{\prime 2}\left(\pi_{\omega}(t) L(t)\right)}{\varphi_{0}\left(\pi_{\omega}(t) L(t)\right)} e^{\xi}\left[1+d_{1}\left(t, z_{1}\right)\right],
$$

$$
\lim _{t \uparrow \omega} d_{1}\left(t, z_{1}\right)=0 \text { uniformly on } z_{1} \in\left[-\frac{1}{2}, \frac{1}{2}\right] \text {. }
$$


Thus, it is shown that for anyone $\varepsilon>0$ there are exist $t_{1} \in\left[t_{0} ; \omega\left[\right.\right.$ and $0<\delta \leq \frac{1}{2}$, such that

$$
\left|R\left(t, z_{1}\right)\right| \leq(1+\varepsilon)\left|z_{1}\right|^{2} \quad \text { as } \quad t \in\left[t_{1} ; \omega\left[,\left|z_{1}\right| \leq \delta .\right.\right.
$$

Choose the number $\varepsilon>0$ and let's consider the system (17) on the set

$$
\Omega=\left[t_{1} ; \omega\left[\times D, \quad \text { where } D=\left\{\left(z_{1} ; z_{2}\right) \in R^{2}, \quad\left|z_{1}\right| \leq \delta, \quad\left|z_{2}\right| \leq \frac{1}{2}\right\} .\right.\right.
$$

System (17) on the set $\Omega$ has the form

$$
\left\{\begin{array}{l}
z_{1}^{\prime}=L(t) \cdot e_{1}(t) \cdot \frac{\varphi_{0}^{\prime}\left(\pi_{\omega}(t) L(t)\right)}{\varphi_{0}\left(\pi_{\omega}(t) L(t)\right)} \cdot\left[q_{1}(t) z_{1}+z_{2}\right] \\
z_{2}^{\prime}=\frac{L^{\prime}(t)}{L(t)} \cdot \frac{e_{2}(t)}{e_{1}(t)} \cdot\left[A_{21}(t) z_{1}+A_{22}(t) z_{2}+R_{1}\left(t, z_{1}, z_{2}\right)+R_{2}\left(t, z_{1}, z_{2}\right)\right]
\end{array}\right.
$$

in which

$$
\begin{gathered}
A_{21}(t)=\frac{[1+r(t)] \cdot K\left(t, z_{2}\right) e_{1}^{\sigma_{1}}(t)}{e_{2}(t)}, \quad A_{22}(t)=A_{21} \cdot \sigma_{1}-1, \\
R_{1}\left(t, z_{1}, z_{2}\right)=A_{21}(t)-1, \\
R_{2}\left(t, z_{1}, z_{2}\right)=A_{21}(t) z_{1}\left(\left[1+z_{2}\right]^{\sigma_{1}}-1\right)+\frac{A_{21}(t) R\left(t, z_{1}\right)}{1+r(t)}\left[1+z_{2}\right]^{\sigma_{1}}+ \\
+A_{21}(t)\left(\left[1+z_{2}\right]^{\sigma_{1}}-1-\sigma_{1} z_{2}\right)
\end{gathered}
$$

Note that from (11) and (18) it follows that

$$
\begin{gathered}
\lim _{t \uparrow \omega} A_{21}=1, \quad \lim _{t \uparrow \omega} A_{22}=\sigma_{1}-1, \\
\lim _{t \rightarrow+\infty} R_{1}\left(t ; z_{1} ; z_{2}\right)=0 \text { uniformly on }\left(z_{1}, z_{2}\right):\left|z_{i}\right|<\frac{1}{2}, i=1,2 . \\
\lim _{\left|z_{1}\right|+\left|z_{2}\right| \rightarrow 0} \frac{R_{2}\left(t ; z_{1} ; z_{2}\right)}{\left|z_{1}\right|+\left|z_{2}\right|}=0 \text { uniformly on } t \in\left[t_{1} ; \omega[.\right.
\end{gathered}
$$

We apply an additional transformation to the system (20)

$$
\left\{\begin{array}{l}
z_{1}(t)=v_{1}(t) \\
z_{2}(t)=|H(t)|^{-\frac{1}{2}} v_{2}(t)
\end{array}\right.
$$

Finally we have

$$
\left\{\begin{array}{l}
v_{1}^{\prime}=h(t)\left[c_{11}(t) v_{1}+c_{12} v_{2}\right], \\
v_{2}^{\prime}=h(t)\left[\frac{H^{\prime}(t) \operatorname{sign} H(t)}{2|H(t)|^{\frac{3}{2}}} v_{2}+\frac{e_{2}(t)}{e_{1}^{2}(t)} A_{21} v_{1}+\right. \\
\left.+\frac{e_{2}(t)}{e_{1}^{2}(t)} \frac{A_{22}}{|H(t)|^{\frac{1}{2}}} v_{2}+\frac{e_{2}(t)}{e_{1}^{2}(t)} R_{1}\left(t, v_{1},|H(t)|^{-\frac{1}{2}} v_{2}(t)\right)+\frac{e_{2}(t)}{e_{1}^{2}(t)} R_{2}\left(t, v_{1},|H(t)|^{-\frac{1}{2}} v_{2}(t)\right)\right]
\end{array}\right.
$$


where

$$
h(t)=\frac{L^{\prime}(t) e_{1}(t)}{L(t)}|H(t)|^{\frac{1}{2}}, \quad c_{11}=\alpha_{0} \mu_{0} q_{1}(t)|H(t)|^{\frac{1}{2}}, \quad c_{12}=\alpha_{0} \mu_{0}
$$

From the (6)-(8), (11) and (12) it follows that

$$
\begin{gathered}
\int_{t_{1}}^{t} h(\tau) d \tau= \pm \infty, \\
\lim _{t \uparrow \omega} \frac{e_{2}(t)}{e_{1}^{2}(t)} \frac{A_{22}}{|H(t)|^{\frac{1}{2}}}=0, \\
\lim _{t \uparrow \omega} \frac{1}{2} \frac{H^{\prime}(t) \operatorname{sign} H(t)}{|H(t)|^{\frac{3}{2}}}=0, \\
\lim _{\left|v_{1}\right|+\left|v_{2}\right| \rightarrow 0} \frac{R_{2}\left(t, v_{1},|H(t)|^{-\frac{1}{2}} v_{2}(t)\right)}{\left|v_{1}\right|+\left|v_{2}\right|}=0 \text { uniformly on } t \in\left[t_{1} ; \omega[.\right.
\end{gathered}
$$

Then we must to find the $\lim _{t \uparrow \omega} c_{11}(t)$. Let's consider

$$
H^{\prime}(t)=\left(\frac{L^{2}(t)}{L^{\prime}(t)}\right)^{\prime} \cdot \frac{\varphi_{0}^{\prime}\left(\pi_{\omega}(t) L(t)\right)}{\varphi_{0}\left(\pi_{\omega}(t) L(t)\right)}+\left.\frac{L^{2}(t)}{L^{\prime}(t)} \cdot\left(L(t)+\pi_{\omega}(t) L(t)\right) \cdot\left(\frac{\varphi_{0}^{\prime}(y)}{\varphi_{0}(y)}\right)^{\prime}\right|_{y=\pi_{\omega}(t) L(t)},
$$

then

$$
\begin{aligned}
\left.\left(\frac{\varphi_{0}^{\prime}(y)}{\varphi_{0}(y)}\right)^{\prime}\right|_{y=\pi_{\omega}(t) L(t)} & =\frac{H^{\prime}(t)}{\frac{L^{2}(t)}{L^{\prime}(t)} \cdot\left(L(t)+\pi_{\omega}(t) L(t)\right)}-\frac{\varphi_{0}^{\prime}\left(\pi_{\omega}(t) L(t)\right)}{\varphi_{0}\left(\pi_{\omega}(t) L(t)\right)} \times \\
& \times \frac{\frac{L^{2}(t)}{L^{\prime}(t)}}{\frac{L^{2}(t)}{L^{\prime}(t)} \cdot\left(L(t)+\pi_{\omega}(t) L(t)\right)} .
\end{aligned}
$$

Then we have

$$
q_{1}(t)|H(t)|^{\frac{1}{2}}=\frac{L(t)}{L^{\prime}(t) e_{1}(t)} \cdot \frac{H^{\prime}(t)}{|H(t)|^{\frac{3}{2}}}-\frac{1+o(1)}{\frac{\pi_{\omega}(t) L^{\prime}(t)}{L(t)} \cdot e_{1}(t)|H(t)|^{\frac{1}{2}} \cdot \operatorname{sign} H^{\prime}(t)} \quad \text { при } \quad t \uparrow \omega .
$$

The first term from (23) equals to zero according to (11) and (12), the second term equals to $-\frac{1}{\gamma}$ due to the condition (13). So, we have

$$
\lim _{t \uparrow \omega} c_{11}(t)=-\frac{\alpha_{0} \mu_{0}}{\gamma}
$$

Characteristic equation of the boundary matrix of coefficients at $v_{1}$ and $v_{2}$

$$
\left(\begin{array}{cc}
\frac{-\alpha_{0} \mu_{0}}{\gamma} & \alpha_{0} \mu_{0} \\
1 & 0
\end{array}\right)
$$

has the form

$$
\lambda^{2}+\frac{\alpha_{0} \mu_{0}}{\gamma} \lambda-\alpha_{0} \mu_{0}=0
$$


This equation has no roots which real part equals to zero.

In the case $\alpha_{0} \mu_{0}>0\left(\alpha_{0} \mu_{0}=1\right)$ the characteristic equation has two real roots with opposite signs. So, according to the theorem 2.2 from [7] the system (22) has one-parameter family of solutions that tend to zero as the argument tends to $+\infty$.

In the case $\alpha_{0} \mu_{0}<0\left(\alpha_{0} \mu_{0}=-1\right)$ the characteristic equation has two real roots with or two complex roots with the real part of the same sign as $\gamma$.

According to the condition $N$

$$
\operatorname{signh}(t)=\alpha_{0} y_{0}^{0} \operatorname{sign\pi } \pi_{\omega}(t)
$$

So, according to results in [7] n case $\alpha_{0} \mu_{0}<0$ and $y_{0}^{0} \alpha_{0} \gamma \pi_{\omega}(t)<0$ the system (22) has a two-parameter family of solutions that tend to zero as the argument tends to $+\infty \mathrm{i}$ and in case $\alpha_{0} \mu_{0}<0$ and $y_{0}^{0} \alpha_{0} \gamma \pi_{\omega}(t)>0$ - has at least one of such solutions.

Each of such solutions of the system (22) due to transformations (16) and (21) corresponds to the solution of the equation (1) which have the representations (14)-(15). It is clear that obtained solutions are indeed $P_{\omega}\left(Y_{0}, Y_{1}, \lambda_{0}\right)$-solutions of the equation (1). The theorem is proved in a whole.

\section{REFERENCE STYLE}

\section{REFERENCES}

[1] Bingham N.H., Goldie C.M., Teugels J.L. Regular variation. Encyclopedia of mathematics and its applications. Cambridge university press, Cambridge, 1987.

[2] Chepok O.O. Asymptotic representations of solutions with slowly varying derivatives of the second order differential equations with rapidly and regularly varying nonlinearities. Research in Mathematics and Mechanics. 2018, 23 2(32), 108-117. doi:10.18524/2519-206x.2018.2(32).149708 (in Ukrainian)

[3] Evtukhov V. M. Asymptotic representations of solutions of non-autonomous ordinary differential equations: dis. Dr. Phys.-Math. Sciences: [spec.] 01.01.02 « Differential equations ». Odessa nat. University named after I.I. Mechnikov. Odessa, 1997.

[4] Evtukhov V. M., Chernikova A. G. On the asymptotics of solutions of second-order ordinary differential equations with rapidly varying nonlinearities. Ukr. Math. journal. 2019,71 (1), 73-91. (in Russian)

[5] Evtukhov V.M., Drik N.G. Asimptotic behavior of solutions of a second order nonlinear differention equation. Georgean mathematical journal. 1996, 3 (2), 123-151

[6] Evtukhov V.M., Samoilenko A.M. Asymptotic representation of solutions of nonautonomous ordinary differential equations with correctly varying nonlinearities. Different. equations. 2011,47 (5), 628-650(in Russian)

[7] Evtukhov V.M., Samoilenko A.M. Conditions for the existence of solutions disappearing at a singular point in real nonautonomous systems of quasilinear differential equations. Ukr. Math. journal. 2010, 62 (1), 52-80. ISSN 1027-3190.(in Russian)

[8] Maric V. Regular Variation and differential equations. Springer (Lecture notes in mathematics, 1726).2000.

[9] Seneta E. Regularly varying functions. Lecture Notes in Math. Berlin: Springer-Verlag. 1976, 508. doi:10.1007/BFb0079658 
Чепок О. О. Асимптотичні зображення розв'язків з повільно змінними похідними диференціальних рівнянь другого порядку з добутком різного типу нелінійностей // Буковинський матем. журнал - 2020. - Т.8, №1. - С. 10-19.

Істотно нелінійні неавтономні диференціальні рівняння почали виникати на практиці з другої половини дев'ятнадцятого століття при дослідженні реальних фізичних процесів атомної і ядерної фізики, а також, астофізики. У роботі розглядається диференціале рівняня, яке містить у правій частині добуток правильно та швидко змінних нелінійностей від невідомої функції та її похідної першого порядку. Окремі випадки таких рівнянь виникають, насамперед, у теорії горіння та теорії плазми. Перші важливі результати щодо асимптотичної поведінки розв'язків таких рівнянь було отримано для диференціального рівняння другого порядку, яке у правій частині містило добуток степеневої та експоненціальної нелінійностей. Для загального випадку таких рівнянь результатів раніше отримано не було. У зв'язку з цим, дослідження асимптотичної поведінки розв'язків нелінійних диференціальних рівнянь другого порядку, що містять добуток правильно та швидко змінних нелінійностей при прямуванні аргументу або до нуля, або до нескінченності, є актуальним не лише з теоретичної, а й з практичної точки зору. У даній роботі досліджуються асимптотичні зображення, а також необхідні і достатні умови існування $P_{\omega}\left(Y_{0}, Y_{1}, \pm \infty\right)$-розв'язків такого рівняння. Цей клас розв'язків є одним з найскладніших для дослідження за рахунок того, що, зважаючи на апріорні властивотсі функцій цього класу, їх похідна другого порядку у явному вигляді не виражається через похідну першого порядку. Результати, отримані у цій статті доповнюють отримані раніше результати для $P_{\omega}\left(Y_{0}, Y_{1}, \pm \infty\right)$-розв'язків досліджуваного рівняння щодо достатніх умов їх існування та кількості. 